\title{
CĂNG THẲNG KINH TẾ, TÍNH VI CHỦNG VÀ ĐÁNH GIÁ SẢN PHẨM ẢNH HƯỞNG ĐẾN SƯ KHÔNG SÃN LÒNG MUA HÀNG HÓA NGOẠI NHẬP CỦA NGƯỜI TIÊU DÙNG TP. HỒ CHÍ MINH
}

\author{
TRÀ̀N HOÀI PHÚC ${ }^{1}$, PHẠM XUÂN KIÊN² ${ }^{2}$ LÊ THI MINH XUÂN ${ }^{1}$ \\ ${ }^{1}$ Trường Đại học Bách Khoa, Đại học Quốc Gia Hồ Chí Minh, \\ ${ }^{2}$ Truờng Đại học Công nghiệp Thành phố Hồ Chí Minh;
}

phamxuankien@iuh.edu.vn

Tóm tắt. Nghiên cứu này nhằm khám phá tác động của Tính vị chủng, Căng thẳng kinh tế và Đánh giá sản phẩm lên sự không sẵn lòng mua hàng hóa Trung Quốc của người tiêu dùng Việt Nam. Dựa trên những sự kiện căng thẳng kinh tế gần đây giữa Việt Nam và Trung Quốc, nghiên cứu này đánh giá lòng tự hào dân tộc của người Việt Nam và sự không sẵn lòng mua hàng hóa Trung Quốc của họ như thế nào. Dựa trên dữ liệu thu thập từ 248 khách hàng, kết quả phân tích mô hình cấu trúc tuyến tính cho thấy sự không sẵn lòng mua hàng hóa Trung Quốc của người tiêu dùng Việt Nam chịu tác động của ba yếu tố là Căng thẳng kinh tế, Tính vị chủng và Đánh giá sản phẩm. Nghiên cứu này có thể hữu ích cho các doanh nghiệp Việt Nam trong việc phát triển các chiến lược kinh doanh và tiếp thị, đặc biệt là các doanh nghiệp nhập khẩu hoặc phân phối các hàng hóa Trung Quốc tại thị trường Việt Nam.

Từ khóa. Căng thẳng kinh tế, Tính vị chủng, Đánh giá sản phẩm, Không sẵn lòng mua.

\section{THE IMPACTS OF ECONOMIC ANIMOSITY, ETHNOCENTRISM AND PRODUCT JUDGEMEN ON CONSUMERS' UNWILLINGNESS TO BUY FOREIGN PRODUCTS - A STUDY IN HO CHI MINH CITY}

\begin{abstract}
This study aims to explore the impacts of Ethnocentrism, Economic Animosity and Product Judgement on Vietnamese consumers' unwillingness to buy Chinese products. Based on recent economic tensions between Vietnam and China, the study assesses how the national pride of the Vietnamese and their unwillingness to buy Chinese products. Based on data collected from 248 customers, the results of linear structural analysis showed that the unwillingness to buy Chinese products of Vietnamese consumers is influenced by three factors, including Ethnocentrism, Economic Animosity and Product Judgement. This study could be useful for VietNam's enterprises in developing strategies for business and marketing, especially, for enterprises importing or distributing Chinese products in the Vietnamese market.
\end{abstract}

Keyword. Economic Animosity, Ethnocentrism, Product Judgement, Unwillingness to buy.

\section{GIỚI THIỆU}

Trong những năm gần đây, tình hình căng thẳng kinh tế giữa Việt Nam và Trung Quốc như hàng hoá Trung Quốc kém chất lượng, điển hình là vụ việc xe tải Trung Quốc giá rẻ kém chất lượng ồ ạt vào Việt Nam [1]. Hay việc Trung Quốc gây rối thị trường, ồ ạt thu mua xuất khẩu tôm nguyên liệu có thể dẫn đến tình trạng mất cân đối nghiêm trọng cơ cấu xuất khẩu, xuất thô nguyên liệu ngày càng tăng, ảnh hưởng xấu đến chiến lược phát triển ngành và hiệu quả đầu tư [2], hoặc các dự án đầu tư của nhà thầu Trung Quốc kém chất lượng, đội vốn cao và chậm tiến độ, điển hình nhất là dự án đường sắt trên cao Cát Linh - Hà Đông [3],... gây ảnh hưởng tiêu cực đến vấn đề kinh tế.

Việc nghiên cứu những yếu tố tác động đến việc đánh giá, chọn lựa hay sẵn lòng mua/không sẵn lòng mua,... giữa hàng hóa nội địa và hàng hóa ngoại nhập đã được nhiều nhà nghiên cứu trong và ngoài nước thực hiện ở nhiều bối cảnh nghiên cứu khác nhau. Ở trong nước, đã có nhiều nghiên cứu về vấn đề này và các yếu tố quan trọng thường được sử dụng trong các nghiên cứu này là tính vị chủng tiêu dùng $[4,5]$; độ nhạy văn hóa $[5] ; \ldots$ Trong các nghiên cứu gần đây, nhiều nhà nghiên cứu trên thế giới đã đưa yếu tố căng thẳng quốc gia vào nghiên cứu, tức là xem xét sự căng thẳng giữa hai quốc gia về vấn đề kinh tế tác động 
lên sự đánh giá và sẵn lòng mua/không sẵn lòng mua hàng ngoại nhập, trong đó phải kể đến các nghiên cứu của $[6,7,8], \ldots$ Tuy nhiên, ở Việt Nam thì vấn đề nghiên cứu ảnh hưởng của yếu tố này lên tính vị chủng, đánh giá sản phẩm hay sẵn lòng mua/không sẵn lòng hàng hóa,... vẫn chưa được quan tâm và đưa vào nhiều trong các nghiên cứu.

Thực tế vấn đề căng thẳng kinh tế nêu trên đang diễn ra như thế nào và mức độ ảnh hưởng của nó như thế nào đến sự sẵn lòng mua của người tiêu dùng Việt Nam thì đến nay ở Việt Nam vẫn chưa có nhiều nghiên cứu chính thức đến vấn đề này. Vì vậy, việc nghiên cứu về vấn đề này hiện này sẽ phần nào giúp các doanh nghiệp sản xuất hàng nội địa cũng như cũng như các doanh nghiệp, cá nhân nhập khẩu hay phân phối hàng hóa ngoại nhập (cụ thể là hàng hóa Trung Quốc) có thể hiểu rõ tác động của yếu tố căng thẳng quốc gia (chủ yếu là căng thẳng kinh tế) và cũng là lúc đánh giá tính vị chủng cũng như thái độ đánh giá về chất lượng hàng hóa của người tiêu dùng Việt Nam đối với hàng hóa ngoại nhập (cụ thể là hàng hóa Trung Quốc) để từ đó có chiến lược kinh doanh hợp lý.

\section{CƠ SỞ LÝ THUYẾT VÀ CÁC GIẢ THUYẾT}

\subsection{Các khái niệm nghiên cứu}

Tính vị chủng tiêu dùng (Consumer ethnocentrism): Khái niệm tính vị chủng tiêu dùng có xuất xứ từ khái niệm tính vị chủng, vốn là một khái niệm tâm lý - xã hội nhằm diễn tả tính cách của một cá nhân trong một bối cảnh văn hoá - xã hội [9]. Khái niệm tính vị chủng được định nghĩa là khuynh hướng của một người xem cộng đồng văn hoá của họ là trung tâm của vũ trụ, là quy chiếu cho các cộng đồng khác. Họ có xu hướng đánh giá thấp các giá trị, chuẩn mực của các nhóm cộng đồng văn hoá khác, và đánh giá cao, tự hào một cách mù quáng các giá trị, chuẩn mực và con người thuộc nhóm văn hoá của mình [10].

Từ đó, khái niệm tính vị chủng tiêu dùng là sự vận dụng khái niệm tính vị chủng vào môi trường kinh tế để biểu thị tính vị chủng trong hành vi tiêu dùng [11]. Tính vị chủng tiêu dùng được định nghĩa là niềm tin của người tiêu dùng về sự đúng đắn về đạo lý trong việc mua các sản phẩm nước ngoài. Theo đó, người có tính vị chủng tiêu dùng cao sẽ cho rằng việc mua sản phẩm nước ngoài là sai trái; điều đó sẽ gây tác hại cho sản xuất trong nước, gây mất công ăn việc làm trong nước, là không yêu nước [10].

Căng thẳng kinh tế (Economic Animosity): Sự căng thẳng quốc gia được định nghĩa như là những tàn tích cả sự ác cảm liên quan đến các sự kiện chính trị, quân sự, kinh tế, ngoại giao đã hoặc đang diễn ra, được cho là có ảnh hưởng trực tiếp và tiêu cực lên hành vi mua của khách hàng trên thị trường quốc tế [12, 13]. Sự căng thẳng quốc gia liên quan đến cảm xúc tiêu cực mạnh mẽ đối với việc mua các sản phẩm từ một hoặc một nhóm quốc gia mà họ không thích. Phần lớn những khảo sát về sự căng thẳng quốc gia nhằm kiểm tra thái độ của các thành viên của một quốc gia hướng tới sản phẩm của một quốc gia khác $[6,7]$. Trong nghiên cứu này, chỉ đề cập đến những căng thẳng về các sự kiện căng thẳng kinh tế giữa Việt Nam và Trung Quốc.

Căng thẳng kinh tế là những căng thẳng xuất phát từ những bất đồng về thương mại giữa các quốc gia với nhau [6,14]. Kết quả nghiên cứu của Klein và Morris [14] cho thấy người Mỹ có thái độ căng thẳng về kinh tế đối với Nhật Bản vì họ cho rằng trong quan hệ thương mại giữa Nhật Bản và Hoa Kỳ vẫn còn tồn đọng vấn đề về sự không công bằng đối với Hoa Kì. Căng thẳng kinh tế có xu hướng phổ biến ở các nước nhỏ hoặc các quốc gia mà người dân có thể không hài lòng với thực trạng nền kinh tế của nước họ bị chi phối bởi một quốc gia lớn hơn và mạnh hơn. Căng thẳng kinh tế có thể dẫn đến sự thù hằn chung và dẫn đến việc không muốn mua hàng hóa của nước có sự căng thẳng chung được nói đến [15].

Đánh giá sản phẩm (Product judgement): Trong nghiên cứu này, khái niệm đánh giá sản phẩm chỉ liên quan đển chất lượng cảm nhận đối với sản phẩm, đó là một tập hợp các thuộc tính của một sản phẩm tạo cho nó khả năng thỏa mãn những nhu cầu tường minh và tiềm ẩn của khách hàng [16]. Monroe và Krishnan [17] cho rằng chất lượng cảm nhận là đánh giá của khách hàng về khả năng sản phẩm có thể đáp ứng nhu cầu và tạo ra sự hài lòng cho họ. Mặt khác, cảm nhận sự công bằng về giá hay giá cảm nhận phản ánh cảm nhận chủ quan của người tiêu dùng về mức độ hợp lý hay sự tương xứng giữa sản phẩm với giá bán của nó [18].

Không sẵn lòng mua (Unwillingness to buy): Theo Ajzen [19], một hành vi có thể được dự đoán bởi các ý định trước đó. Quan điểm của lý thuyết hành vi hoạch định cho rằng ý định và khuynh hướng cá nhân là chỉ báo dự đoán hành vi. Ý định được thừa nhận là động cơ dẫn đến hành vi, là dấu hiệu của mức độ sẵn 
sàng mua/không sẵn sàng mua. Như vậy, nhân tố quan trọng nhất ảnh hưởng lên hành vi là ý định hay khuynh hướng hành vi.

\subsection{Các giả thuyết và mô hình nghiên cứu}

\section{Căng thẳng kinh tế và Tính vị chủng}

Lý thuyết tiếp thị mô tả căng thẳng quốc gia (cụ thể là những căng thẳng về mặt kinh tế) và tính vị chủng được xem là những khái niệm thể hiện trạng thái tâm lý và hành vi phản ứng đối với xuất xứ của một quốc gia cụ thể [15]. Căng thẳng quốc gia là những gì còn sót lại của sự ác cảm hoặc thù hận đối với một quốc gia $[6,13]$. Cảm xúc này có thể ảnh hưởng đến hành động như một bản năng tự vệ và làm gia tăng sự đoàn kết trong một cộng đồng, hành vi tự vệ và tính vị chủng [15]. Các nghiên cứu này đã nhấn mạnh về sự cần thiết để nghiên cứu vấn đề căng thẳng quốc gia như là tiền thân của tính vị chủng, bởi vì chúng có thể có liên quan với nhau $[6,20]$. Như vậy, tình trạng căng thẳng quốc gia (tập trung vào tình trạng căng thẳng kinh tế) được xem là một yếu tố quan trọng để xem xét khi nghiên cứu đánh giá của người tiêu dùng đối với các sản phẩm nước ngoài, đặc biệt là nó có thể làm gia tăng tính vị chủng của người tiêu dùng [15]. Vì vậy, giả thuyết $\mathrm{H} 1$ có thể được phát biểu như sau:

H1: Tình trạng căng thẳng kinh tế giữa Trung Quốc và Việt Nam càng cao thì sẽ làm tăng tính vị chủng của người tiêu dùng Việt Nam.

\section{Tính vị chủng và Đánh giá sản phẩm}

Tính vị chủng của người tiêu dùng là những niềm tin, quan niệm sẵn có về sự đúng đắn và phù hợp về đạo đức trong việc mua hàng nước ngoài $[10,21]$. Khái niệm này có các đặc điểm sau: Một là kết quả của lòng yêu nước và sự lo ngại mất khả năng kiểm soát các lợi ích kinh tế của quốc gia mình do các tác động xấu của việc nhập khẩu mang đến; hai là tạo ra tâm niệm không mua hàng ngoại. Đối với người có tính vị chủng cao, việc mua hàng ngoại không chỉ đơn thuần là vấn đề về kinh tế mà nó còn mang giá trị đạo đức, không mua hàng ngoại là yêu nước, là hành vi đúng đắn; trái lại mua hàng ngoại là không đúng đắn, là đi ngược lại với lợi ích quốc gia; Ba là dẫn đến định kiến chống lại việc nhập khẩu. Do đó kết quả của tính vị chủng là sự đánh giá thiên vị, nâng cao hàng nội và hạ thấp hàng ngoại, luôn ưu tiên hàng nội và không sẵn lòng mua hàng ngoại. Người có tính vị chủng càng cao thì càng đánh giá thấp hàng ngoại nhập. Kết quả đánh giá thiên vị đó góp phần hỗ trợ trực tiếp làm gia tăng thái độ bài xích hàng ngoại. Vì vậy, giả thuyết H2 có thể được phát biểu như sau:

H2: Người tiêu dùng Việt Nam có tính vị chủng càng cao thì họ sẽ đánh giá hàng hóa Trung Quốc càng thấp.

\section{Căng thẳng kinh tế và Đánh giá sản phẩm}

Người tiêu dùng có thể nhận thấy rằng sản phẩm xuất xứ của một quốc gia nào đó có chất lượng, nhưng do sự căng thẳng với quốc gia giữa quốc gia của họ và một quốc gia khác sẽ phần nào ảnh hưởng đến việc đánh giá sản phẩm của họ đối với hàng hóa sản phẩm quốc gia khác. Nghiên cứu của Rose et al. [7] chỉ ra rằng sự căng thẳng quốc gia (cụ thể là căng thẳng kinh tế) có ảnh hưởng tiêu cực đến sự đánh giá phẩm của quốc gia khác.

Thời gian gần đây, các phương tiện thông tin đại chúng đưa tin việc Trung Quốc làm loạn giá nông sản tại Việt Nam hoặc các công trình được nhà thầu Trung Quốc thi công như: đường sắt trên cao Cát Linh - Hà Đông bị chậm tiến độ, đội vốn không đảm bảo an toàn lao động. Những sự kiện kinh tế này có thể gây tiêu cực đến sự đánh giá hàng hóa Trung Quốc của người tiêu dùng Việt Nam [3]. Nghiên cứu này nhằm kiểm định sự tác động của yếu tố căng thẳng kinh tế lên sự đánh giá hàng hoá Trung Quốc. Vì vậy, giả thuyết $\mathrm{H} 3$ có thể được phát biểu như sau:

H3: Tình trạng căng thẳng kinh tế giũa Trung Quốc và Việt Nam càng cao thì người tiêu dùng Việt Nam sẽ đánh giá hàng hóa Trung Quốc càng thấp.

\section{Đánh giá sản phẩm và Không sẵn lòng mua}

Nguồn gốc xuất xứ của một sản phẩm đã lý giải được những ý niệm định kiến của khách hàng về sản phẩm của quốc gia đó [22]. Theo Maheswaran [23] chỉ ra rằng nhận thức tích cực về một quốc gia dẫn đến sự thuận lợi hơn trong việc đánh giá hàng hoá và dịch vụ của quốc gia đó. Nghiên cứu của Nijssen và Douglas [15] cho thấy có sự tương quan nghịch biến giữa việc đánh giá sản phẩm nước ngoài và sự miễn 
cưỡng mua hàng hóa nước ngoài hoặc nghiên cứu của Rose et al. [7] cũng chỉ ra rằng việc đánh giá tích cực/tiêu cực sẽ ảnh hưởng tích cực/tiêu cự đến sự sẵn lòng mua/không sãn lòng mua của người tiêu dùng giữa các nhóm văn hóa khác nhau. Vì vậy, giả thuyết $\mathrm{H} 4$ có thể được phát biểu như sau:

H4: Nguời tiêu dùng Việt Nam đánh giá hàng hóa Trung Quốc càng cao thì sụ không sã̃n lòng mua của ho càng thấp.

\section{Căng thẳng kinh tế và Không sẵn lòng mua}

Nhìn chung, phần lớn những nghiên cứu trước đây đã khám phá ra rằng sự căng thẳng quốc gia (cụ thể là căng thẳng kinh tế) có tác động tiêu cực đến sự sẵn lòng mua của khách hàng trong quốc gia này đối với sản phẩm của quốc gia có tình trạng căng thẳng $[6,12,15]$. Vì vậy, giả thuyết $\mathrm{H} 5$ có thể được phát biểu như sau:

H5: Tình trạng căng thẳng kinh tế giũa Trung Quốc và Việt Nam càng cao thì sụ không sã̃n lòng mua hàng hóa Trung Quốc của người tiêu dùng Việt Nam càng cao.

\section{Tính vị chủng và Không sã̃n lòng mua}

Klein et al. [6] cho rằng tính vị chủng người tiêu dùng góp phần vào xu hướng tránh mua các sản phẩm nước ngoài nói chung của người tiêu dùng. Nhiều nghiên cứu cũng cho thấy tính vị chủng có tác động tiêu cực đến sự sẵn lòng mua hàng ngoại nhập và tích cực đến sự sẵn lòng mua hàng nội của người tiêu dùng [10]. Vì vậy, giả thuyết $\mathrm{H6}$ có thể được phát biểu như sau:

H6: Tính vị chủng của người tiêu dùng Việt Nam càng cao thì sụ không sã̃n lòng mua hàng hóa Trung Quốc của người tiêu dùng Việt Nam càng cao.

\section{Mô hình nghiên cứu}

Dựa vào sáu giả thuyết được hình thành và biện luận ở trên, mô hình nghiên cứu được xây dựng như trong Hình 1. Trong mô hình nghiên cứu này, Căng thẳng kinh tế đồng thời ảnh hưởng trực tiếp đến Tính vị chủng $(\mathrm{H} 1)$, Đánh giá sản phẩm $(\mathrm{H} 3)$ và Không sẵn lòng mua (H5); tiếp đến, Tính vị chủng có ảnh hưởng trực tiếp đồng thời đển Đánh giá sản phẩm $(\mathrm{H} 2)$ và Không sã̃n lòng mua $(\mathrm{H} 4)$; cuối cùng là Đánh giá sản phẩm ảnh hưởng trực tiếp lên Không sẵn lòng mua (H4) của người tiêu dùng Việt Nam đối với hàng hóa Trung Quốc.

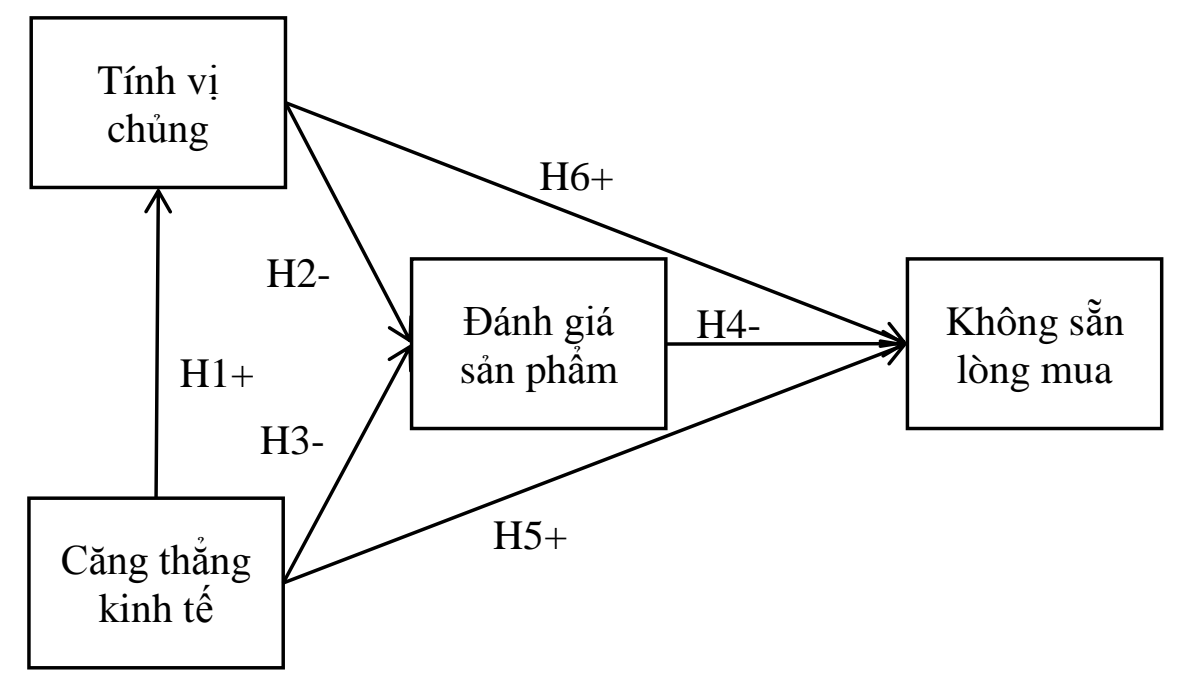

Hình 1. Mô hình nghiên cứu

\section{PHƯƠNG PHÁP NGHIÊN CÚU}

Mô hình và các giả thuyết được kiểm định dựa trên bộ dữ liệu có kích thước 248 mẫu. Mẫu được thu thập qua một cuộc khảo sát theo phương pháp lấy mẫu thuận tiện tại Tp. Hồ Chí Minh. Đối tượng khảo sát là người tiêu dùng Việt Nam có độ tuổi từ 18 tuổi trở lên đã có tìm hiểu hoặc đã sử dụng sản phẩm của Trung Quốc. Phương pháp tiếp cận là phỏng vấn trực tiếp tại nơi làm việc, học tập, tại nhà hoặc nơi thuận tiện khác. 
Nội dung của các thang đo được kế thừa từ nghiên cứu của Rose et al. (2009), có hiệu chỉnh và bổ sung thông qua bước phỏng vấn sơ bộ (nghiên cứu định tính), cụ thể là có bổ sung 2 biến quan sát trong thang đo Căng thẳng kinh tế (xem ở Bảng 2). Theo đó, thang đo Tính vị chủng gồm 6 biến quan sát, Căng thẳng kinh tế gồm 7 biến quan sát, Đánh giá sản phẩm gồm 6 biến quan sát và Không sẵn lòng mua gồm 6 biến quan sát. Tất cả thang đo đều có dạng Likert 7

Kỹ thuật xử lý dữ liệu được sử dụng trong nghiên cứu chính thức (nghiên cứu định lượng) bao gồm: thống kê mô tả mẫu; các bước đánh giá độ tin cậy của thang đo (Cronbach's Alpha), phân tích nhân tố khám phá (EFA), phân tích nhân tố khẳng định (CFA) được sử dụng để kiểm tra độ tin cậy và độ giá trị của thang đo; và phân tích mô hình cấu trúc tuyến tính (SEM) được sử dụng để kiểm định các giả thuyết trong mô hình nghiên cứu.

\section{KẾT QUẢ}

\section{Mô tả mẫu}

Như trình bày trong Bảng 1 , nhìn chung đối tượng khảo sát phần lớn là những người tiêu dùng trẻ tuổi từ 18-34 tuổi $(77,4 \%)$, nam giới chiếm tỷ lệ $58,7 \%$. Nhóm đã mua hàng có trình độ học vấn đại học chiếm tỷ lệ cao nhất $(58,9 \%)$, thu nhập hàng tháng nằm trong khoảng 4-9 triệu VNĐ $(37,1 \%), 9-20$ triệu VNĐ $(40,3 \%)$ và đa số là nhân viên văn phòng $(56,5 \%)$.

Bảng 1. Mô tả mẫu $(\mathrm{n}=248)$

\begin{tabular}{|c|c|c|c|c|c|}
\hline & $\begin{array}{c}\text { Tần } \\
\text { số }\end{array}$ & $\begin{array}{l}\text { Tỷ lệ } \\
\text { (\%) }\end{array}$ & & $\begin{array}{c}\text { Tần } \\
\text { số }\end{array}$ & $\begin{array}{l}\text { Tỷ lệ } \\
\text { (\%) }\end{array}$ \\
\hline \multicolumn{3}{|l|}{ Giới tính } & \multicolumn{3}{|l|}{ Độ tuổi } \\
\hline Nam & 152 & 58,7 & 18-34 tuổi & 192 & 77,4 \\
\hline Nũ & 107 & 41,3 & 35-49 tuổi & 53 & 21,4 \\
\hline \multirow{2}{*}{ Tổng } & \multirow{2}{*}{259} & \multirow{3}{*}{100} & Lớn hơn 49 tuổi & 3 & 1,2 \\
\hline & & & Tổng & 248 & 100 \\
\hline \multicolumn{2}{|l|}{ Học vấn } & & \multicolumn{3}{|l|}{ Ngành nghề } \\
\hline Dưới Trung cấp & 1 & 0,4 & Công nghệ thông tin & 24 & 9,7 \\
\hline Trung cấp & 4 & 1,6 & Quảng cáo/Truyền thông/Giải trí & 11 & 4,4 \\
\hline Cao đẳng & 20 & 8,1 & Điện tử/Công nghệ cao & 22 & 8,9 \\
\hline Đại học & 146 & 58,9 & Sản xuất & 30 & 12,1 \\
\hline Sau Đại học & 77 & 31,0 & Xây dựng/Vật liệu & 37 & 14,9 \\
\hline \multirow{2}{*}{ Tổng } & \multirow{2}{*}{248} & \multirow{3}{*}{100} & Khác & 124 & 50,0 \\
\hline & & & Tổng & 248 & 100 \\
\hline \multicolumn{2}{|l|}{ Chức vụ } & & \multicolumn{3}{|c|}{ Thu nhập hàng tháng } \\
\hline Quản lý cấp cao & 9 & 3,6 & Dưới 4 triệu VNĐ & 0 & 0.0 \\
\hline Quản lý cấp trung/Quản lý cấp cơ sở & 77 & 31,0 & Từ 4 triệu đến dưới 9 triệu VNĐ & 92 & 37,1 \\
\hline Nhân viên văn phòng & 140 & 56,5 & Từ 9 triệu đến dưới 20 triệu VNĐ & 100 & 40,3 \\
\hline Công nhân/Lao động phổ thông & 3 & 1,2 & Từ 20 triệu đến dưới 40 triệu VNĐ & 48 & 19,4 \\
\hline Khác & 19 & 7,7 & Từ 40 triệu đến dưới 60 triệu VNĐ & 1 & 0,4 \\
\hline \multirow[t]{2}{*}{ Tổng } & 248 & 100 & Từ 60 triệu VNĐ trở lên & 7 & 2,8 \\
\hline & & & Tổng & 248 & 100 \\
\hline
\end{tabular}

\section{Đánh giá và gạn lọc thang đo}

Các thang đo được đánh giá sơ bộ bằng độ tin cậy Cronbach's Alpha và phân tích nhân tố khám phá (EFA). Với 25 biến quan sát ban đầu, sau khi loại 7 biến (dùng để đo tính vị chủng, căng thẳng kinh tế và không sẵn lòng mua) (Xem Bảng 2) do có hệ số tải nhân tố thấp $(<0,5)$, các thang đo với 18 biến còn lại được đưa vào kiểm định chính thức với phân tích nhân tố khẳng định (CFA). 
Trong phân tích nhân tố khẳng định (CFA), tiếp tục loại thêm 2 biến (dùng để đo tính vị chủng và đánh giá sản phẩm) do có tương quan giữa các sai số cao, kết quả cho thấy mô hình thang đo với 16 biến quan sát đạt độ phù hợp với dữ liệu thực tế; cụ thể, mô hình này có 98 bậc tự do, Chi-square $=191,836$; Chisquare/df $=1,958<2, \mathrm{p}=0,000<0,05$; tuy nhiên các chỉ số, $\mathrm{GFI}=0,911>0,9, \mathrm{CFI}=0,972>0,9$, TLI $=$ $0,966>0,9$ và $\mathrm{RMSEA}=0,062<0,08$, điều này cho thấy mô hình đo lường này phù hợp với dữ liệu thị trường.

Dựa vào kết quả ở Bảng 2 , hệ số tải chuẩn hóa của các biến dao động từ 0,702 đến 0,950 đều lớn hơn 0,5 , đồng thời phương sai trích của các thang đo (AVE) dao động từ 0,671 đến 0,825 đều lớn hơn 0,5 nên các thang đo đạt giá trị hội tụ. Độ tin cậy tổng hợp $(\mathrm{CR})$ dao động từ 0,877 đến 0,959 đều lớn hơn 0,7 , nên các thang đo đạt độ tin cậy. Đồng thời, không có bất kỳ phương sai nào được góp chung bởi hai khái niệm lớn hơn tổng phương sai trích của các khái niệm này, điều này cho thấy các khái niệm đều đạt độ giá trị phân biệt.

Bảng 2. Kết quả đánh giá thang đo

\begin{tabular}{|c|c|}
\hline Thang đo và biến quan sát & $\begin{array}{l}\text { Hệ số tải } \\
\text { chuẩn hóa }\end{array}$ \\
\hline \multicolumn{2}{|l|}{ Tính vị chủng: Cronbach's Alpha =0,860 ; CR =0,877; AVE = 0,704 } \\
\hline $\begin{array}{l}\text {-Tôi nghĩ hàng hóa Việt Nam luôn là sự lựa chọn ưu tiên của tôi } \\
\text {-Tôi nghĩ việc mua hàng hóa nước ngoài thì không phải là hành động của người Việt Nam yêu nước } \\
\text {-Tôi nghĩ việc mua hàng hóa ngoại nhập là góp phần làm cho một số người Việt Nam bị mâtt việc } \\
\text { làm } \\
\text {-Tôi nghĩ việc mua hàng hóa ngoại nhập chỉ giúp cho nước khác làm giàu } \\
\text {-Tôi nghĩ người Việt Nam chỉ nên mua hàng hóa ngoại nhập khi nó không thể sản xuất được trong } \\
\text { nước } \\
\text {-Tôi nghĩ người tiêu dùng Việt Nam nào mua hàng hóa sản xuất từ các nước khác thì đều có một } \\
\text { phần trách nhiệm cho những người Việt Nam bị mất việc làm }\end{array}$ & $\begin{array}{c}0,898 \\
*\end{array}$ \\
\hline \multicolumn{2}{|l|}{ Căng thẳng kinh tế: Cronbach's Alpha $=0,935 ; \mathrm{CR}=0,959 ; \mathrm{AVE}=0,825$} \\
\hline $\begin{array}{l}\text {-Tôi không thich người Trung Quốc **** } \\
\text {-Tôi nghĩ Trung Quốc không phải là một đối tác thương mại đáng tin cậy } \\
\text {-Tôi nghĩ Trung Quốc muốn khống chế/kiểm soát nền kinh tế Việt Nam } \\
\text {-Tôi nghĩ Trung Quốc đang lợi dụng nền kinh tế Việt Nam } \\
\text {-Tôi nghĩ Trung Quốc đang gây tồn thất cho nền kinh tế Việt Nam **** } \\
\text {-Tôi nghĩ Trung Quốc đang có nhiều ảnh hưởng lên nền kinh tế của Việt Nam } \\
\text {-Tôi nghĩ các doanh nghiệp/thương nhân Trung Quốc đang kinh doanh không trung thực với các } \\
\text { doanh nghiệp/thương nhân Việt Nam }\end{array}$ & $\begin{array}{c}* \\
* \\
* \\
0,950 \\
0,946 \\
0,912 \\
0,864 \\
0,865\end{array}$ \\
\hline \multicolumn{2}{|l|}{ Đánh giá sản phẩm: Cronbach's Alpha = 0,908; $\mathrm{CR}=0,910 ; \mathrm{AVE}=0,671$} \\
\hline $\begin{array}{l}\text {-Tôi nghĩ hàng hóa Trung Quốc được sản xuất một cách cẩn thận } \\
\text {-Tôi nghĩ hàng hóa Trung Quốc có chất lượng cao } \\
\text {-Tôi nghĩ hàng hóa Trung Quốc được sản xuất trên các dây chuyền công nghệ hiện đại } \\
\text {-Tôi nghĩ hàng hóa Trung Quốc được thiết kế đẹp } \\
\text {-Tôi nghĩ hàng hóa Trung Quốc đáng tin cậy } \\
\text {-Tôi nghĩ hàng hóa Trung Quốc có chất lượng tương xứng với giá bán }\end{array}$ & $\begin{array}{c}0,809 \\
0,856 \\
0,848 \\
* * \\
0,870 \\
0,702 \\
\end{array}$ \\
\hline \multicolumn{2}{|l|}{ Không sã̃n lòng mua: Cronbach's Alpha $=0,835 ; \mathrm{CR}=0,897 ; \mathrm{AVE}=0,745$} \\
\hline $\begin{array}{l}\text {-Tôi cảm thấy có lỗi với đất nước nếu tôi mua hàng hóa Trung Quốc } \\
\text {-Tôi sẽ không bao giờ mua hàng hóa Trung Quốc } \\
\text {-Bất cứ khi nào có thể (có nhiê̂u lựa chọn khác nhau), tôi sẽ tránh mua hàng hóa Trung Quốc } \\
\text {-Bất cứ khi nào có thể (có nhiều lựa chọn khác nhau), tôi thích mua hàng hóa Trung Quốc hơn } \\
\text {-Tôi không có ý định sở hữu hàng hóa Trung Quốc } \\
\text {-Nếu hai sản phẩm cùng chất lượng, một sản phẩm của Việt Nam và một sản phẩm của Trung Quốc, } \\
\text { tôi sẽ sẵn sàng chi trả nhiều hơn } 10 \% \text { để mua sản phẩm của Việt Nam. }\end{array}$ & $\begin{array}{l}0,862 \\
0,900 \\
* \\
* \\
0,825 \\
*\end{array}$ \\
\hline
\end{tabular}

Ghi chú: *: loại qua EFA; **: loại qua CFA; ***: Biến quan sát được bổ sung 


\section{Kiểm định mô hình cấu trúc tuyến tính}

Kết quả phân tích mô hình cấu trúc tuyến tính cho thấy mô hình này có 98 bậc tự do, Chi-square = 191,836; Chi-square/df = 1,958 $<2, \mathrm{p}=0,000<0,05$; tuy nhiên các chỉ số, GFI = 0,911 > 0,9, CFI = 0,972 $>0,9, \mathrm{TLI}=0,966>0,9$ và $\mathrm{RMSEA}=0,062<0,08$, điều này cho thấy mô hình này phù hợp với dữ liệu thị trường và $43 \%$ sự biến thiên của yếu tố Không sẵn lòng mua được giải thích bởi các yếu tố có trong mô hình nghiên cứu.

Kết quả ước lượng mô hình cấu trúc tuyến tính ở Bảng 3 cho thấy các mối quan hệ kiểm định đều có hệ số hồi quy chuẩn hoá dương và đều có ý nghĩa về mặt thống kê $(\mathrm{p}<0,05)$, do đó các giả thuyết từ $\mathrm{H1}$ đến H6 đều được ủng hộ.

Bên cạnh đó, phân tích cấu trúc đa nhóm cũng được thực hiện với các nhóm trình độ học vấn khác nhau. Tuy nhiên, kết quả cho thấy không có sự khác biệt đáng kể giữa các nhóm trình độ học vấn về các mối quan hệ được kiểm định trong mô hình.

Bảng 3. Kết quả kiểm định mô hình cấu trúc tuyến tính

\begin{tabular}{|c|c|c|c|}
\hline Mối quan hệ & $\begin{array}{l}\text { Trọng số hồi quy } \\
\text { chuẩn hóa }\end{array}$ & $\mathbf{p}$ & $\begin{array}{c}\text { Kiểm định giả } \\
\text { thuyết }\end{array}$ \\
\hline Căng thẳng kinh tế $\rightarrow$ Tính vị chủng & 0,41 & 0,002 & Ủng hộ H1 \\
\hline Tính vị chủng $\rightarrow$ Đánh giá sản phẩm & $-0,21$ & 0,002 & Ủng hộ H2 \\
\hline Căng thẳng kinh tế $\rightarrow$ Đánh giá sản phẩm & $-0,52$ & 0,003 & Ủng hộ H3 \\
\hline Đánh giá sản phẩm $\rightarrow$ Không sẵn lòng mua & $-0,32$ & 0,001 & Ủng hộ H4 \\
\hline Căng thẳng kinh tế $\rightarrow$ Không sẵn lòng mua & 0,24 & 0,009 & Ủng hộ H5 \\
\hline Tính vị chủng $\rightarrow$ Không sã̃n lòng mua & 0,25 & 0,002 & Ủng hộ H6 \\
\hline
\end{tabular}

\section{THẢO LUẬN KẾT QUẢ}

Căng thẳng kinh tế là nguồn gốc sâu xa ảnh hưởng trực tiếp và gián tiếp đến Không sẵn lòng mua hàng hóa Trung Quốc của người tiêu dùng Việt Nam. Vấn đề Căng thẳng kinh tế giữa Trung Quốc và Việt Nam đã tồn tại hàng chục năm qua và có thể thấy những vấn đề này về lâu dài cũng khó đi đến hồi kết. Những vấn đề này càng tồn tại lâu dài bao nhiêu thì thái độ và suy nghĩ tiêu cực của người tiêu dùng Việt Nam đối với hàng hóa Trung Quốc càng ăn sâu vào tâm trí của họ. Đồng thời có thể thấy vấn đề Căng thẳng kinh tế càng tăng thì tính vị chủng của người tiêu dùng Việt Nam càng cao. Kết quả này cho thấy các doanh nghiệp của Việt Nam có thể phối hợp với Chính phủ, các tổ chức kinh tế - xã hội, truyền, phân tích những vấn đề về kinh tế mà phía Trung Quốc đang gây ra cho Việt Nam đồng thời kết hợp đẩy mạnh các chương trình "Người Việt dùng hàng Việt", "Người Việt Nam ưu tiên dùng hàng Việt Nam",... để qua đó người tiêu dùng Việt Nam có nhận định chính xác hơn về những bất lợi mà phía Trung Quốc đang gây ra cho Việt Nam đồng thời cho họ thấy những hậu quả gây bất lợi cho doanh nghiệp Việt Nam cũng như người dân Việt Nam, đồng thời khơi dậy lòng yêu nước cũng như tinh thần tự hào dân tộc của họ.

Yếu tố đánh giá sản phẩm có tác động lớn nhất đến sự không sẵn lòng mua hàng hóa Trung Quốc so với tính vị chủng và căng thẳng kinh tế cho thấy người tiêu dùng Việt Nam vẫn quan tâm đến vấn đề chất lượng nhiều hơn trong hành vi mua của họ. Họ đánh giá dựa trên lý trí mà cụ thể là thể hiện qua việc đánh giá chất lượng chứ không bị ảnh hưởng bởi cảm xúc. Vì vậy, các doanh nghiệp Việt Nam khi phát triển sản phẩm của doanh nghiệp mình không thể dựa trên những yếu tố tính vị chủng hay tranh thủ tình hình căng thẳng kinh tế giữa Trung Quốc và Việt Nam mà trong khi đó sản phẩm của doanh nghiệp không được khách hàng đánh giá cao. Điều đó có nghĩa là các doanh nghiệp Việt Nam không nên tập trung quá nhiều vào việc tuyên truyền, khuyến khích người Việt tiêu dùng hàng Việt, trong khi lại không tập trung chú trọng đến chất lượng sản phẩm của doanh nghiệp mình. Tính vị chủng và căng thẳng kinh tế chỉ đóng góp một phần chứ không phải là tất cả có ảnh hưởng đến việc không sẵn lòng mua hàng hóa Trung Quốc của người Việt Nam.

Mặc dù, việc không sẵn lòng mua hàng hóa Trung Quốc của người tiêu dùng Việt Nam vẫn chưa đảm bảo chắc chắn rằng họ sẽ mua hàng hóa của các doanh nghiệp Việt Nam sản xuất. Tuy nhiên, trong điều kiện thu nhập còn thấp của người dân Việt Nam hiện nay thì việc người tiêu dùng Việt Nam không sẵn lòng mua hàng hóa Trung Quốc thì khả năng họ sẽ quay sang sẵn lòng mua hàng hóa Việt Nam là hoàn toàn có cơ sở vì hàng hóa Việt Nam trong những năm gần đây được đánh giá là có chất lượng khá tốt và giá thành 
tương đối thấp so với hàng hóa của các nước khác. Như vậy, các doanh nghiệp Việt Nam có thể dựa trên tiêu chí đánh giá chất lượng của hàng hóa Trung Quốc của người tiêu dùng Việt Nam để từ đó thiết kế sản phẩm của doanh nghiệp mình có chất lượng phù hợp với kỳ vọng của người Việt Nam kết hợp với tính vị chủng của người Việt Nam ngày càng cao và tình hình căng thẳng giữa Trung Quốc và Việt Nam ngày càng cao thì khả năng người Việt Nam tiêu dùng hàng hóa Việt Nam sẽ tăng lên.

Kết quả phân tích cấu trúc đa nhóm cho thấy không có sự khác biệt giữa các nhóm trình độ học vấn. Điều này có nghĩa là tác động của căng thẳng kinh tế, tính vị chủng và đánh giá sản phẩm lên không sẵn lòng mua của người tiêu dùng Việt Nam đối với hàng hóa Trung Quốc là như nhau giữa các nhóm trình độ học vấn. Điều này có ý nghĩa rất quan trọng cho các nhà sản xuất hàng hóa của Việt khi thực hiện các chương trình tiếp thị nhằm kêu gọi "người Việt dùng hàng Việt", "người Việt Nam ưu tiên dùng hàng Việt Nam",... đó là không cần phải sử dụng các chiến lược tiếp thị khác nhau cho các phân khúc trình độ học vấn trên.

\section{KẾT LUẦN}

Đề tài được thực hiện nhằm xác định và kiểm định mối quan hệ giữa các yếu tố tính vị chủng, đánh giá sản phẩm và căng thẳng kinh tế đối với sự không sẵn lòng mua hàng hoá ngoại nhập. Khám phá sự khác biệt về mối quan hệ giữa tính vị chủng, đánh giá sản phẩm và căng thẳng kinh tế đối với sự sẵn lòng mua hàng hoá ngoại nhập theo trình độ học vấn.

Kết quả nghiên cứu gợi ý một số phương án cho các doanh nghiệp kinh doanh tại thị trường Việt Nam một số phương án nhằm thúc đẩy và phát triển kinh doanh, đặc biệt là các doanh nghiệp sản xuất kinh doanh hàng Việt Nam. Dựa trên yếu tố căng thẳng kinh tế như việc thương lái Trung Quốc làm loạn giá nông sản, hay việc một mặt hàng Trung Quốc nhập vào Việt Nam kém chất lượng, hay các công trình do các nhà thầu Trung Quốc thi công kém chất lượng,... để thúc đẩy lòng tự hào tự tôn dân tộc của người Việt Nam, ưu tiên người Việt dùng hàng Việt. Bên cạnh đó các doanh nghiệp cũng không thể bỏ quên một yếu tố quan trọng đó là đánh giá sản phẩm, vì người tiêu dùng vẫn ưu tiên sử dụng những sản phẩm có chất lượng là trên hết.

Bên cạnh những thành tựu đạt được, nghiên cứu này cũng còn một số hạn chế. Thứ nhất, trong nghiên cứu sử dụng phương pháp lấy mầu thuận tiện nên có thể độ tin cậy của dữ liệu chưa cao, nên các nghiên cứu tiếp theo có thể thực hiện với các phương pháp lấy mẫu khác có độ tin cậy cao hơn. Thứ hai, nghiên cứu chỉ thu thập mẫu ở Tp.HCM nên chưa thể tổng quát hóa về thái độ của người tiêu dùng Việt Nam; vì vậy, các nghiên cứu sau có thể mở rộng phạm vi nghiên cứu ra các tỉnh thành khác để tăng độ tổng quát hơn.

\section{TÀI LIỆU THAM KHẢO}

[1] Ủy ban an toàn giao thông quốc gia (29/05/2014) Xe tải Trung Quốc kém chất lượng ồ ạt vào Việt Nam [Online]. Khai thác từ: http://antoangiaothong.gov.vn./den-do/xe-tai-trung-quoc-kem-chat-luong-o-at-vao-viet-nam41723.html.

[2] Sở Công Thương Bến Tre (10/12/2013) Buôn bán với Trung Quốc: Phải biết “cách chơi” [Online]. Khai thác từ: http://www.congthuongbentre.gov.vn/home/buon-ban-voi-trung-quoc-phai-biet-cach-choi--W1791.htm.

[3] VTV1 (10/07/2017) Dự án đường sắt trên cao Cát Linh - Hà Đông chậm tiến độ [Online]. Khai thác từ: http://vtv.vn/trong-nuoc/vi-sao-du-an-duong-sat-tren-cao-cat-linh-ha-dong-tiep-tuc-cham-tien-do20170919003815089.htm.

[4] L. N. Hậu, T. T. Quỳnh, và L. Đ. Anh, Người Việt dùng hàng Việt: Vai trò của tính vị chủng và lượng giá đối với sự sẵn lòng mua hàng Việt Nam, Science \& Technology, vol. 14, no. 3, pp. 56-67, 2011.

[5] N. Đ. Thọ và N. T. M. Trang, Nghiên cưu khoa học Marketing: Úng dụng mô hình cấu trúc tuyến tính SEM. Nhà xuất bản Lao Động, 2011.

[6] J. G. Klein, R. Ettensen, and M. D. Morris, The animosity model of foreign product purchase: An empirical test 

KHÔNG SÃ̃N LÒNG MUA HÀNG HÓA NGOẠI NHẬP CỦA NGỬì TIÊU DÙNG TP. HỒ CHÍ MINH

in the People's Republic of China, Journal of Marketing, vol. 62, no. 1, pp. 89-100, 1998.

[7] M. Rose, G. M. Rose, and A. Shoham, The impact of consumer animosity on attitudes towards foreign goods: A study of Jewish and Arab Israelis, Journal of Customer Marketing, vol. 26, no. 5, pp. 330-339, 2009.

[8] V. Abraham, Does Consumer Animosity Impact Purchase Involvement? An Empirical Investigation, International Journal of Business and Social Science, vol. 4, no. 1, pp. 1-11, 2013.

[9] G. W. Sumner, Folkways:The Sociological Importance of Usage, Manner, Custom, Mores, and Morals. Ginn and Co, 1906.

[10] T. A. Shimp and S. Sharma, Consumer ethnocentrism: Construction and validation of the CETSCALE, Journal of Marketing Research, vol. 24, no. 3, pp. 280-289, 1987.

[11] G. Chryssochoidis, A. Krystallis, and P. Perreas, Ethnocentrism beliefs and country-of-origin (COO) effect: Impact of country, product and product attributes on Greek consumers' evaluation of food products, European Journal of Marketing, vol. 41, no. 11, pp. 1518-1544, 2007.

[12] R. Ettensen and J. G. Klein, The fallout from French nuclear testing in the South Pacific: a longitudinal study of consumer boycott, International Marketing Review, vol. 22, no. 2, pp. 199-224, 2005.

[13] P. Riefler and A. Diamantopoulos, Consumer animosity: A literature review and a reconsideration of its measurement, International Marketing Review, vol. 34, no. 1, pp. 87-119, 2007.

[14] J. G. Klein and M. D. Morris, Consumer animosity and consumer ethnocentrism: an analysis of unique antecedents, Journal of International Consumer Marketing, vol. 11, no. 4, pp. 5-24, 1996.

[15] E. Nijssen and S. Douglas, Examining the animosity model in a country with a high level of foreign trade, International Journal of Research in Marketing, vol. 21, pp. 23-38, 2004.

[16] V. A. Zeithaml, Consumer perceptions of price, quality, and value: A means-end model and synthesis of evidence, The Journal of Marketing, vol. 52, no. 3, pp. 2-22, 1988.

[17] B. K. Monroe and R. Krishnan, The effect of price on subjective product evaluations. D. C. Health and Company, 1985.

[18] J. Jacoby and J. C. Olson, Consumer response to price: An attitudinal information processing perspective. American Marketing Association, 1977.

[19] I. Ajzen, The Theory of Planned Behavior, Organizational behavior and human decision processes, vol. 50, pp. 179-211, 1991.

[20] M. N. Shankarmahesh, Consumer ethnocentrism: An integrative review of its antecedents and consequences, International Marketing Review,vol. 23, no. 2, pp. 146-172, 2006.

[21] S. Sharma, T. A. Shimp, and J. Shin, Consumer ethnocentrism: A test of antecedents and moderators, Journal of the Academy of Marketing Science, vol. 23, no. 1, pp. 26-37, 1995.

[22] G. E. Nakos and Y. A. Hajidimitriou, The Impact of National Animosity on Consumer Purchases: The Modifying Factor of Personal, Journal of International Consumer Marketing, vol. 19, no. 3, pp. 53-72, 2007.

[23] D. Maheswaran, Business and Economic Studies The Leonard N. Stern School of Business. New York University, 2006.

Ngày nhận bài: 17/11/2017

Ngày chấp nhận đăng: 18/01/2018 